\title{
The role of D-serine as co-agonist of NMDA receptors in the nucleus accumbens: relevance to cocaine addiction
}

\author{
Marcello D'Ascenzo*, Maria Vittoria Podda and Claudio Grassi
}

Institute of Human Physiology, Medical School, Universitá Cattolica "S. Cuore," Rome, Italy

\section{Edited by:}

Fabrice R. Turpin, University of Queensland, Australia

Reviewed by:

Qian Sun, HHMI, Columbia

University, USA

Jean-Pierre Mothet, CNRS - Aix

Marseille University, France

\section{*Correspondence:}

Marcello D'Ascenzo, Institute of

Human Physiology, Medical School,

Università Cattolica "S. Cuore",

Largo Francesco Vito 1, 00168

Rome, Italy

e-mail:dascenzo@rm.unicatt.it
Cocaine addiction is characterized by compulsive drug use despite adverse consequences and high rate of relapse during periods of abstinence. Increasing consensus suggests that addiction to drugs of abuse usurps learning and memory mechanisms normally related to natural rewards, ultimately producing long-lasting neuroadaptations in the mesocorticolimbic system. This system, formed in part by the ventral tegmental area and nucleus accumbens (NAc), has a central role in the development and expression of addictive behaviors. In addition to a broad spectrum of changes that affect morphology and function of NAc excitatory circuits in cocaine-treated animals, impaired N-methyl-Daspartate receptor (NMDAR)-dependent synaptic plasticity is a typical feature. D-serine, a D-amino acid that has been found at high levels in mammalian brain, binds with high affinity the co-agonist site of NMDAR and mediates, along with glutamate, several important processes including synaptic plasticity. Here we review recent literature focusing on cocaine-induced impairment in synaptic plasticity mechanisms in the NAc and on the fundamental role of D-serine as co-agonist of NMDAR in functional and dysfunctional synaptic plasticity within this nucleus. The emerging picture is that reduced D-serine levels play a crucial role in synaptic plasticity relevant to cocaine addiction. This finding opens new perspectives for therapeutic approaches to treat this addictive state.

Keywords: addiction, cocaine, D-serine, NMDA receptors, nucleus accumbens, synaptic plasticity

\section{INTRODUCTION}

A large body of evidence has demonstrated the fundamental role of D-serine as co-agonist at the N-methyl-D-aspartate receptor (NMDAR), a major glutamate receptor subtype involved in synaptic plasticity (Mothet et al., 2000; Panatier et al., 2006; Fossat et al., 2012; Rosenberg et al., 2013). In particular, D-serine, by binding the so called "glycine site" on the NR1 subunit, is crucial for the activation of these receptors and for NMDARdependent synaptic plasticity mechanisms. D-serine degradation by the FAD-dependent enzyme D-amino acid oxidase (DAAO) suppresses NMDAR-dependent component of excitatory synaptic currents and prevents NMDAR-dependent long term potentiation (LTP) and depression (LTD) in different brain areas, including the hippocampus, the supraoptic nucleus and prefrontal cortex (Yang et al., 2003; Panatier et al., 2006; Fossat et al., 2012).

Abnormal levels of D-serine have been reported in aging (Potier et al., 2010; Turpin et al., 2011; Haxaire et al., 2012; Billard, 2013), Alzheimer's disease (Wu et al., 2004) and amyotrophic lateral sclerosis (ALS; Sasabe et al., 2012; Paul and de Belleroche, 2014). Moreover, D-serine has emerged as an influential player in the context of psychiatric diseases such as schizophrenia and depression. Indeed, based on the rationale that a common feature of these pathologies might be a dysregulation of glutamatergic system, especially NMDAR-dependent synaptic transmission, an increasing number of studies have investigated D-serine signaling to explore possible causes and potential therapeutic interventions for these diseases (Carlsson and Carlsson, 1990; Adage et al., 2008; Lisman et al., 2008; Gunduz-Bruce, 2009; Hashimoto et al., 2009; Labrie et al., 2012; Balu et al., 2013; Lane et al., 2013; Sacchi et al., 2013).

More recently a link between $\mathrm{D}$-serine signaling and cocaine addiction, another neuropsychiatric disorder, has been proposed. Cocaine addiction is a pathological learned behavior characterized by compulsive drug seeking and high vulnerability to relapse even after prolonged abstinence (Mendelson and Mello, 1996). A large body of evidence has linked the development and expression of this addictive behavior to neuroadaptations in the mesocorticolimbic system. The interconnected brain regions that make up this system include the prefrontal cortex, the ventral tegmental area, and the ventral striatum (also known as nucleus accumbens, NAc), which has been critically implicated in the expression of a variety of addiction-related behavioral alterations (Koob and Volkow, 2010). In particular, cocaineinduced neuroadaptations in the NAc have been associated with changes in glutamatergic synaptic transmission and plasticity (Kauer and Malenka, 2007; Lüscher and Malenka, 2011). In this context, accumulating evidence indicates an impairment of NMDAR-dependent LTP and LTD at glutamatergic synapses in the NAc of animal models of cocaine addiction (Martin et al., 2006; Moussawi et al., 2009; Kasanetz et al., 2010). 
A link between D-serine and cocaine addiction was first indicated by findings that $\mathrm{D}$-serine reduced the expression of cocaineinduced conditioned place preference (a standard behavioral model used to study the rewarding and aversive effects of drugs) (Yang et al., 2013), and that reduced cocaine-primed reinstatement following extended access to cocaine self-administration (Kelamangalath and Wagner, 2010). Within this context we have recently addressed the issue of whether D-serine signaling could be involved in cocaine-induced neuroadaptations in the NAc of a rat model of non-contingent (passive) cocaine exposure (Curcio et al., 2013).

\section{D-SERINE-RELATED PATHWAY IN THE NAC}

Since the initial detection of D-serine in the central nervous system (Hashimoto and Oka, 1997) subsequent immunostaining studies have more precisely localized D-serine, DAAO and serine racemase (SR), the major biosynthetic enzyme for D-serine, in mammalian brain (Williams et al., 2006; Verrall et al., 2007; Paul and de Belleroche, 2014). SR was initially identified in astrocytes and microglia (Wolosker et al., 1999; Stevens et al., 2003; Wu et al., 2004; Panatier et al., 2006). More recently, however, SR was also identified in neurons (Kartvelishvily et al., 2006; Dun et al., 2008; Wolosker, 2011; Miya et al., 2008; Rosenberg et al., 2013; Balu et al., 2014) challenging the classical view that D-serine is a gliotransmitter.

In the NAc the presence of D-serine, DAAO and SR was found in both neurons and astrocytes (Curcio et al., 2013). This cellular localization in the NAc is consistent with the model of D-serine dynamics proposed by Wolosker (2011) that is based upon the notion that D-serine is primarily made in neurons and explains why drugs blocking astrocyte metabolism affect D-serine extracellular level (Zhang et al., 2008; Henneberger et al., 2010). This so-called "serine shuttle model" proposes that astrocytes synthesize and export L-serine to neurons to fuel the synthesis of D-serine by the neuronal SR. Once synthesized and released by neurons, D-serine can be taken up by astrocytes for storage and activity-dependent release (Martineau et al., 2013). Our results also showed that the intensity of immunostaining for D-serine and its related enzymes among labeled neuronal cells ( $>80 \%$ of NAc core neurons) was different, likely reflecting different levels of expression. Considering that there are two main types of MSNs: those expressing D1-like receptors and those that express D2-like dopamine receptors (Sesack et al., 1994; Hara and Pickel, 2005; D'Ascenzo et al., 2009; Podda et al., 2010), and that these cell subtypes show different responses to cocaine exposure (Lobo et al., 2010; Maze et al., 2014), it would be of interest to establish whether these two neuronal subtypes differentially express D-serine machinery.

As in other brain areas, the presence of D-serine in the NAc is related to its ability to act as NMDAR co-agonist at synaptic level. Indeed, electrophysiological data provided by our group showed a marked increase in AMPA/NMDA ratio at excitatory synapses in brain slices where D-serine levels had been lowered by incubation with $R g$ DAAO. In contrast enzymatic degradation of glycine with glycine oxidase did not affect AMPA/NMDA ratio (Curcio et al., 2013). The same study also revealed the essential role of $\mathrm{D}$-serine in synaptic plasticity mechanisms within the NAc by showing that enzymatic D-serine degradation prevented the induction of NMDAR-dependent LTP and LTD.

\section{REDUCED D-SERINE LEVELS IN A RAT MODEL OF COCAINE-ADDICTION}

Although our knowledge on the molecular mechanisms underlying the behavioral changes induced by cocaine abuse is far from be complete, research on rodent models has successfully identified alterations in NMDAR-dependent synaptic plasticity as an important component of these behavioral changes.

Several studies have indeed demonstrated impairment of LTP and LTD in different models of cocaine addiction. In vivo experimental evidence showed that after long-term withdrawal from cocaine self-administration LTP cannot be induced in the rat NAC core (Moussawi et al., 2009). The impairment of LTP reported in this study has been attributed to a pre-existing LTP-like state, developed during cocaine treatment and/or withdrawal, in which the synaptic strength is maximized. Moussawi et al. (2009) also observed loss of LTD inducibility in the rat NAc after longterm withdrawal from self-administered cocaine, an effect that could not be explained by pre-existing synaptic potentiation. Impairment of LTD has also been reported by other authors in rats with a history of cocaine in both in vivo and ex vivo (i.e., brain slices) preparations (Martin et al., 2006; Kasanetz et al., 2010). It is well known that in many regions of the brain the induction of both LTP and LTD is dependent on the activation of NMDARs which leads to postsynaptic $\mathrm{Ca}^{2+}$ influx. LTP is mediated by large, short-lived increases in the intracellular $\mathrm{Ca}^{2+}$ concentration that is believed to occur following activation of synaptic NR2Acontaining NMDARs, whereas moderate $\mathrm{Ca}^{2+}$ increases through extrasynaptic NR2B-containing NMDARs have been involved in the induction of LTD (Massey et al., 2004; Yashiro and Philpot, 2008; Hunt and Castillo, 2012). Such different regulation of intracellular $\mathrm{Ca}^{2+}$ levels are supposed to trigger different subset of $\mathrm{Ca}^{2+}$-dependent intracellular signaling molecules required for both forms of synaptic plasticity.

NMDAR hypofunction with reduced $\mathrm{Ca}^{2+}$ influx at the postsynaptic level is an attractive hypothesis to explain the impairment of both LTP and LTD in cocaine-treated animals.

In keeping with this, recent findings from our laboratory have raised the intriguing possibility that cocaine treatment is associated with changes in D-serine signaling, that contribute to synaptic plasticity dysfunction (Figure 1). In slices from cocainetreated rats exposure to saturating levels of exogenous D-serine fully restored LTP and LTD inducibility (Figure 1C). Moreover, NMDAR neurotransmission driven by endogenous D-serine was impaired in the NAc slices from cocaine-treated rats (Curcio et al., 2013).

Further support to the involvement of NMDAR hypofunction in mediating changes in synaptic plasticity observed in our cocaine treatment paradigm comes from data demonstrating an increase in AMPA/NMDA ratio in cocaine-treated rats that was not associated with changes in AMPA receptor function and expression. Additionally, biochemical assays revealed that D-serine levels in the NAc extract obtained from cocaine-treated 
A

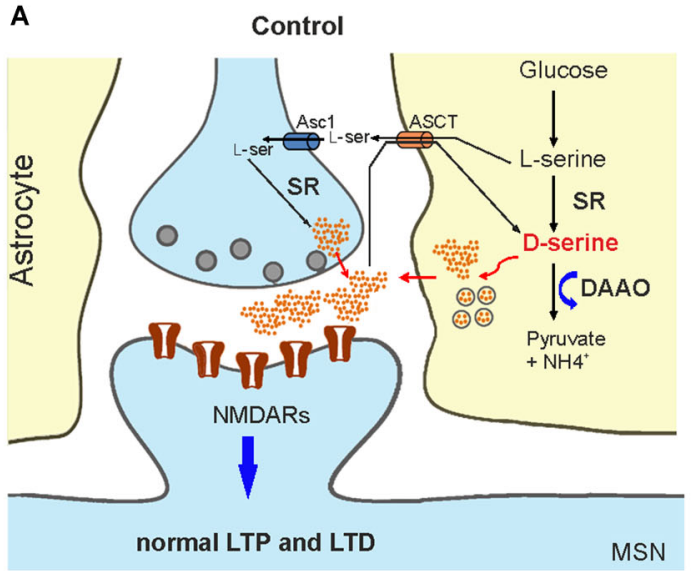

C

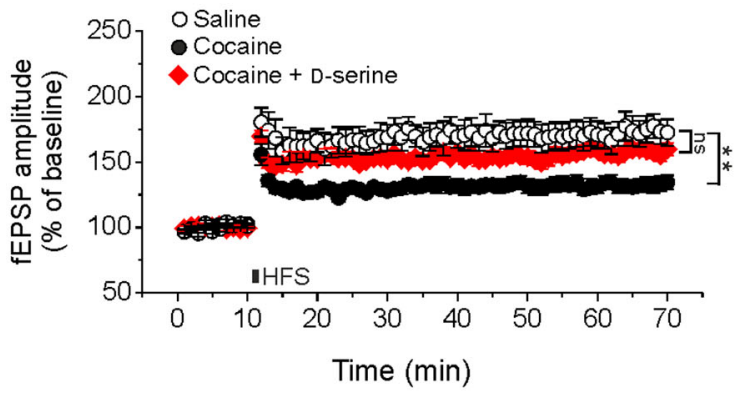

FIGURE 1 | Cocaine-induced deficits in NMDAR-dependent synaptic plasticity in the NAc result from reduced D-serine levels. Compared to control animals $(\mathbf{A})$ in cocaine-treated rats $(\mathbf{B})$ reduced levels of D-serine at glutamatergic synapses impinging on medium spiny neurons leads to NMDAR hypofunction that, in turn, causes impairments of LTP and LTD elicited by standard stimulation protocols. Dashed arrows in $\mathbf{B}$ indicate reduced expression of the enzyme whereas thick arrows indicate increased
B
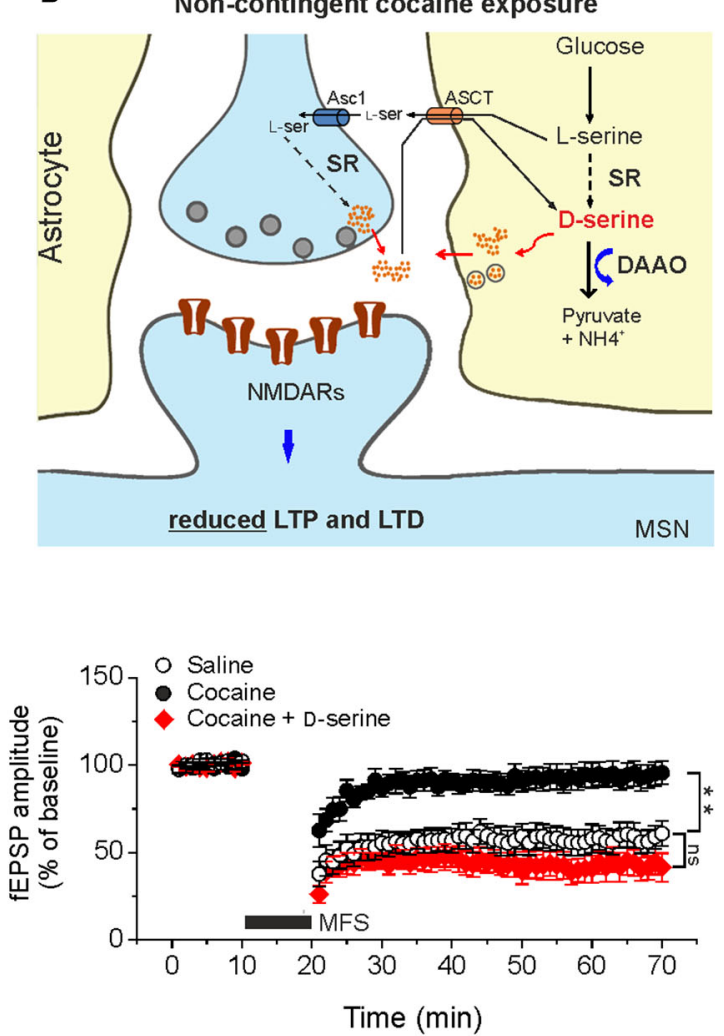

levels of the enzyme. Asc1, alanine-serine-cysteine-1 transporter-1. ASCT, alanine/serine/cysteine/threonine transporter. (C) Time course of LTP and LTD in NAc slices from saline- (control) and cocaine-treated rats. High frequency stimulation (HFS) and medium frequency stimulation (MFS) inducing LTP (left) and LTD (right), respectively, are impaired in slices from cocaine-treated rats, but not when the medium is supplemented with D-serine (red, ${ }^{*} p<0.001$ ). Data are adapted from Curcio et al. (2013). rats were significantly lower than those found in extracts from saline-treated rats.

The molecular determinants of D-serine synaptic turnover affected by cocaine treatment has yet to be definitively identified. However, considering that DAAO expression was increased in cocaine treated rats at both the transcriptional and posttranscriptional levels, whereas SR expression was reduced only at post-transcriptional level, it may be speculated that the main contribution to cocaine-related decrease in D-serine content arises from both increased degradation and decreased synthesis (Figure 1B; Curcio et al., 2013).

Although molecular and functional data from our and other studies established a clear link between impaired D-serine signaling and altered LTP and LTD in the NAc, the understanding of cocaine-induced neuroplasticity changes is a very complex and debated issue since different neuroadaptive changes at molecular and cellular levels can occur at the same time in the NAc (Nestler, 2005; Kreek et al., 2012). Furthermore, adding complexity to this scenario, conflicting results have been reported depending on the drug-exposure protocols (e.g., self-administration or passive), animal models used and duration of withdrawal (e.g., short or long-term) (Thomas et al., 2001; Kourrich et al., 2007; Bowers et al., 2010; Wolf and Tseng, 2012; Ortinski et al., 2013).

\section{REDUCED D-SERINE SIGNALING IN THE NAc AS MOLECULAR CORRELATE FOR COCAINE-INDUCED LOCOMOTOR SENSITIZATION}

Locomotor sensitization (usually measured as increased locomotor responses to repeated administration of cocaine) has been related to impairment of synaptic plasticity in the NAc (Thomas et al., 2001; Kalivas et al., 2009). Moreover, this behavioral paradigm has provided a major impetus to explore the neuroplasticity that may occur during the transition from drug use to addiction (Koob and Volkow, 2010) and several studies have demonstrated the essential role played by the NAc in both the induction and expression phases of this cocaine-induced behavioral alteration (Kalivas et al., 2009).

By injecting D-serine directly into the NAc, we demonstrated that this amino acid blocks the development of locomotor sensitization to cocaine (Figure 2). These findings indicate 

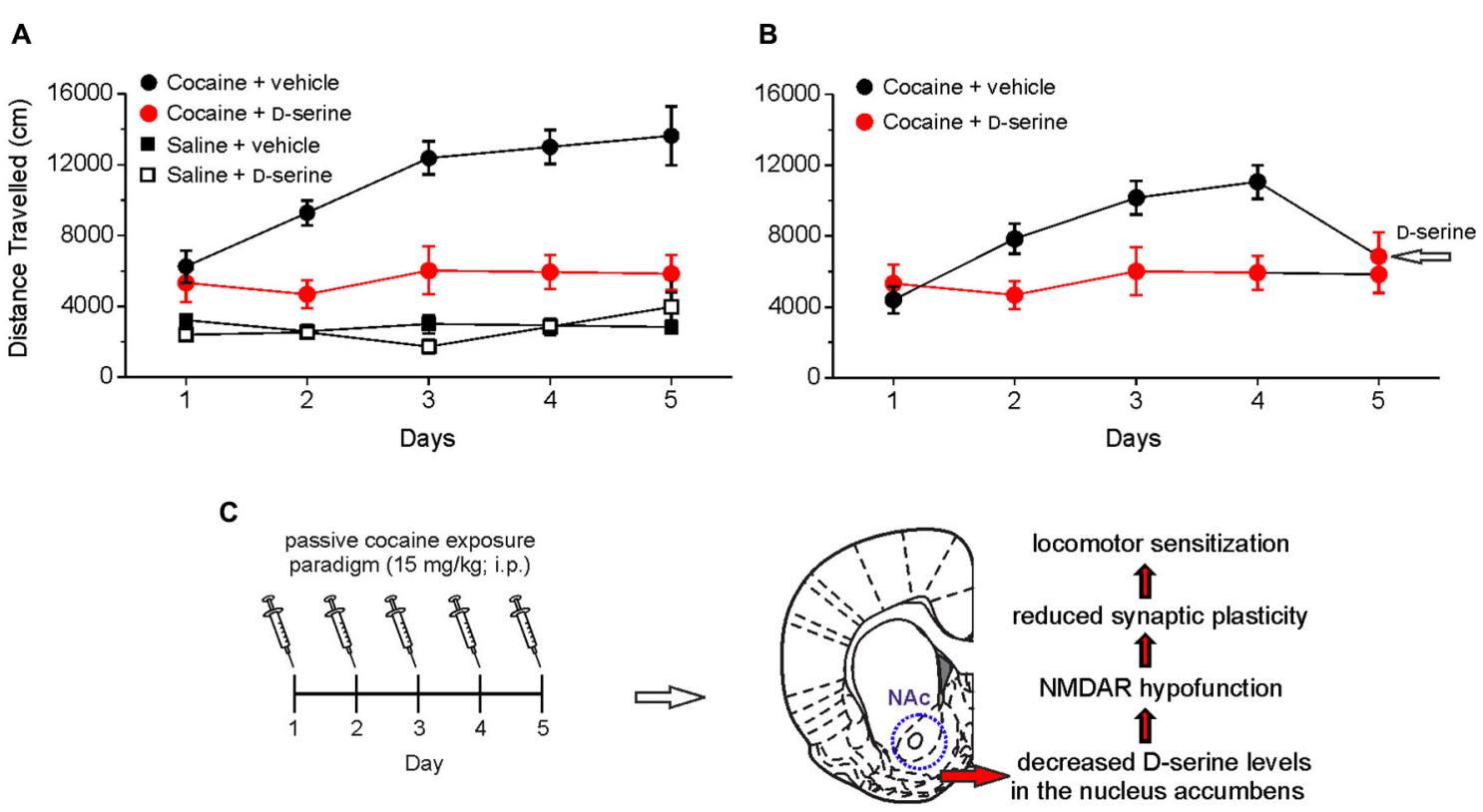

FIGURE 2 | Intra-accumbens microinjection of D-serine blocks locomotor sensitization, an hallmark behavioral feature associated with chronic exposure to cocaine. (A) Analysis of locomotor activity measured by using an open field apparatus showing the distance traveled by different groups of rats treated with saline or cocaine $(15 \mathrm{mg} / \mathrm{kg}$, intraperitoneal, i.p.) and receiving intra-accumbens $\mathrm{D}$-serine $(0.4 \mu \mathrm{g} / 0.3 \mu \mathrm{l})$ or vehicle. When rats are intra-NAc microinjected with

\begin{abstract}
D-serine prior to cocaine treatment (red), the development of cocaine sensitization is blocked (i.e., the distance traveled on days $2-5$ is not significantly different from day 1). (B) A single intra-NAc injection of $D$-serine at day 5 reverts the effect of cocaine on locomotor activity (days 1-4). (C) Summary of cocaine-induced D-serine signaling dysregulation in the NAc and consequent functional alterations. Data are taken from Curcio et al. (2013).
\end{abstract}

that cocaine-induced impairment of D-serine signaling may be a molecular correlate for cocaine-induced behavioral sensitization and strongly support the notion that NMDAR-associated glycine recognition site plays an important role in the cocaine induced behavioral changes. In keeping with this, it has been reported that partial agonists at NMDAR glycine site have beneficial effects in rescuing cocaine-induced behavioral alterations (Khan and Shoaib, 1996; Huang et al., 2008; Thanos et al., 2009; Nic Dhonnchadha et al., 2010; Torregrossa et al., 2010). The finding that D-serine reverts both the cocaineinduced synaptic plasticity impairment and locomotor sensitization points to this amino acid as an attractive tool for counteracting the behavioral changes induced by cocaine in humans. However, in this respect it should be pointed out that, although still under debate (D'Souza et al., 2013), the use of long-term treatment with large doses of D-serine has been reported to cause side-effects, especially the oxidationdependent necrosis of renal proximal tubules (Williams and Lock, 2004; Krug et al., 2007). A possible strategy to overcome potential side effects would be to employ low doses of D-serine together with oral administration of DAAO inhibitors. This therapy has been successfully used to reduce cognitive symptoms in animal models of schizophrenia (Adage et al., 2008; Ferraris et al., 2008; Hashimoto et al., 2009). Furthermore, a recent study showed that sodium benzoate, a DAAO inhibitor, per se significantly improved a variety of symptom domains and neurocognition in patients with chronic schizophrenia (Lane et al., 2013). Taken together these findings hold promise for treating cocaine addiction by targeting $\mathrm{D}$-serine signaling.

\section{CONCLUSIONS}

Cocaine is the second most commonly used illegal drug worldwide after cannabis. Prevalence of cocaine use (last year, lifetime) is particularly high among aged between 15 and 34 years. Cocaine addiction is a worldwide public health problem with consequences beyond its somatic and psychiatric effects including socio-economic and judicial complications. The number of longterm cocaine-dependent patients entering drug treatment has been increasing in Europe for several years. However, there is no specific pharmacotherapy with established efficacy for the treatment of cocaine addiction and basic research on this field represents one of the most important tool to face and counteract this important public health problem.

During the last 5 years data have accumulated assigning a significant role to D-serine in mediating synaptic plasticity and behavioral changes associated with cocaine addiction. These findings encourage the development of new pharmacological interventions targeting D-serine signaling to treat addiction. However, many questions still remain to be answered, especially those regarding the synaptic turnover of this amino acid in the brain. For example, what is the selective contribution of astrocytes and neurons to D-serine release? Is D-serine released through vesicular and/or nonvescicular mechanisms? How SR and DAAO 
expression and activity are regulated? The understanding of these mechanisms is essential before considering the development of D-serine-derived drugs for the treatment of cocaine addiction and other psychiatric disorders or cognitive deficits associated to impaired NMDAR-dependent synaptic plasticity.

\section{REFERENCES}

Adage, T., Trillat, A. C., Quattropani, A., Perrin, D., Cavarec, L., and Shaw, J. (2008). In vitro and in vivo pharmacological profile of AS057278, a selective d-amino acid oxidase inhibitor with potential anti-psychotic properties. Eur. Neuropsychopharmacol. 18, 200-214. doi: 10.1016/j.euroneuro.2007.06.006

Balu, D. T., Li, Y., Puhl, M. D., Benneyworth, M. A., Basu, A. C., Takagi, S., et al. (2013). Multiple risk pathways for schizophrenia converge in serine racemase knockout mice, a mouse model of NMDA receptor hypofunction. Proc. Natl. Acad. Sci. U S A 110, E2400-E2409. doi: 10.1073/pnas.1304308110

Balu, D. T., Takagi, S., Puhl, M. D., Benneyworth, M. A., and Coyle, J. T. (2014). D-serine and serine racemase are localized to neurons in the adult mouse and human forebrain. Cell. Mol. Neurobiol. 34, 419-435. doi: 10.1007/s10571-0140027-z

Billard, J. M. (2013). Serine racemase as a prime target for age-related memory deficits. Eur. J. Neurosci. 37, 1931-1938. doi: 10.1111/ejn.12226

Bowers, M. S., Chen, B. T., and Bonci, A. (2010). AMPA receptor synaptic plasticity induced by psychostimulants: the past, present and therapeutic future. Neuron 67, 11-24. doi: 10.1016/j.neuron.2010.06.004

Carlsson, M., and Carlsson, A. (1990). Schizophrenia: a subcortical neurotransmitter imbalance syndrome? Schizophr. Bull. 16, 425-432. doi: 10.1093/schbul/16. 3.425

Curcio, L., Podda, M. V., Leone, L., Piacentini, R., Mastrodonato, A., Cappelletti, P., et al. (2013). Reduced D-serine levels in the nucleus accumbens of cocainetreated rats hinder the induction of NMDA receptor-dependent synaptic plasticity. Brain 136, 1216-1230. doi: 10.1093/brain/awt036

D’Ascenzo, M., Podda, M. V., Fellin, T., Azzena, G. B., Haydon, P., and Grassi, C. (2009). Activation of mGluR5 induces spike afterdepolarization and enhanced excitability in medium spiny neurons of the nucleus accumbens by modulating persistent $\mathrm{Na}^{+}$currents. J. Physiol. 587, 3233-3250. doi: 10.1113/jphysiol.2009. 172593

D’Souza, D. C., Radhakrishnan, R., Perry, E., Bhakta, S., Singh, N. M., Yadav, R., et al. (2013). Feasibility, safety and efficacy of the combination of D-serine and computerized cognitive retraining in schizophrenia: an international collaborative pilot study. Neuropsychopharmacology 38, 492-503. doi: 10.1038/npp. 2012.208

Dun, Y., Duplantier, J., Roon, P., Martin, P. M., Ganapathy, V., and Smith, S. B. (2008). Serine racemase expression and D-serine content are developmentally regulated in neuronal ganglion cells of the retina. J. Neurochem. 104, 970-978. doi: 10.1111/j.1471-4159.2007.05015.x

Ferraris, D., Duvall, B., Ko, Y. S., Thomas, A. G., Rojas, C., Majer, P., et al. (2008). Synthesis and biological evaluation of D-amino acid oxidase inhibitors. J. Med. Chem. 51, 3357-3359. doi: 10.1021/jm800200u

Fossat, P., Turpin, F. R., Sacchi, S., Dulong, J., Shi, T., Rivet, J. M., et al. (2012). Glial D-serine gates NMDA receptors at excitatory synapses in prefrontal cortex. Cereb. Cortex 22, 595-606. doi: 10.1093/cercor/bhr130

Gunduz-Bruce, H. (2009). The acute effects of NMDA antagonism: from the rodent to the human brain. Brain Res. Rev. 60, 279-286. doi: 10.1016/j.brainresrev.2008. 07.006

Hara, Y., and Pickel, V. M. (2005). Overlapping intracellular and differential synaptic distributions of dopamine D1 and glutamate N-methyl-Daspartate receptors in rat nucleus accumbens. J. Comp. Neurol. 492, 442-455. doi: 10. $1002 /$ cne. 20740

Hashimoto, K., Fujita, Y., Horio, M., Kunitachi, S., Iyo, M., Ferraris, D., et al. (2009). Co-administration of a D-amino acid oxidase inhibitor potentiates the efficacy of D-serine in attenuating prepulse inhibition deficits after administration of dizocilpine. Biol. Psychiatry 65, 1103-1106. doi: 10.1016/j.biopsych.2009.01.002

Hashimoto, A., and Oka, T. (1997). Free D-aspartate and D-serine in the mammalian brain and periphery. Prog. Neurobiol. 52, 325-353. doi: 10.1016/s03010082(97)00019-1

Haxaire, C., Turpin, F. R., Potier, B., Kervern, M., Sinet, P. M., and Barbanel, G. (2012). Reversal of age-related oxidative stress prevents hippocampal synaptic plasticity deficits by protecting D-serine-dependent NMDA receptor activation. Aging Cell 11, 336-344. doi: 10.1111/j.1474-9726.2012.00792.x

Henneberger, C., Papouin, T., Oliet, S. H., and Rusakov, D. A. (2010). Long-term potentiation depends on release of D-serine from astrocytes. Nature 463, 232236. doi: $10.1038 /$ nature 08673

Huang, Y. H., Lin, Y., Brown, T. E., Han, M. H., Saal, D. B., Neve, R. L., et al. (2008). CREB modulates the functional output of nucleus accumbens neurons: a critical role of N-methyl-D-aspartate glutamate receptor (NMDAR) receptors. J. Biol. Chem. 283, 2751-2760. doi: 10.1074/jbc.m706578200

Hunt, D. L., and Castillo, P. E. (2012). Synaptic plasticity of NMDA receptors: mechanisms and functional implications. Curr. Opin. Neurobiol. 22, 496-508. doi: 10.1016/j.conb.2012.01.007

Kalivas, P. W., Lalumiere, R. T., Knackstedt, L., and Shen, H. (2009). Glutamate transmission in addiction. Neuropharmacology 56, 169-173. doi: 10.1016/j. neuropharm.2008.07.011

Kartvelishvily, E., Shleper, M., Balan, L., Dumin, E., and Wolosker, H. (2006). Neuron-derived D-serine release provides a novel means to activate N-methylD-aspartate receptors. J. Biol. Chem. 281, 14151-14162. doi: 10.1074/jbc. m512927200

Kasanetz, F., Deroche-Gamonet, V., Berson, N., Balado, E., Lafourcade, M., Manzoni, O., et al. (2010). Transition to addiction is associated with a persistent impairment in synaptic plasticity. Science 25, 1709-1712. doi: 10.1126/science. 1187801

Kauer, J. A., and Malenka, R. C. (2007). Synaptic plasticity and addiction. Nat. Rev. Neurosci. 8, 844-858. doi: 10.1038/nrn2234

Kelamangalath, L., and Wagner, J. J. (2010). D-serine treatment reduces cocaineprimed reinstatement in rats following extended access to cocaine selfadministration. Neuroscience 169, 1127-1135. doi: 10.1016/j.neuroscience.2010. 06.006

Khan, M., and Shoaib, M. (1996). Neuroanatomical localization of the effects of $\left(^{+}\right)$-HA966 on locomotor activity after cocaine injections to the nucleus accumbens of rats. Brain Res. 719, 198-202. doi: 10.1016/0006-8993(96)00028-5

Koob, G. F., and Volkow, N. D. (2010). Neurocircuitry of addiction. Neuropsychopharmacology 35, 217-238. doi: 10.1038/npp.2009.110

Kourrich, S., Rothwell, P. E., Klug, J. R., and Thomas, M. J. (2007). Cocaine experience controls bidirectional synaptic plasticity in the nucleus accumbens. J. Neurosci. 27, 7921-7928. doi: 10.1523/jneurosci.1859-07.2007

Kreek, M. J., Levran, O., Reed, B., Schlussman, S. D., Zhou, Y., and Butelman, E. R. (2012). Opiate addiction and cocaine addiction: underlying molecular neurobiology and genetics. J. Clin. Invest. 122, 3387-3393. doi: 10.1172/ JCI60390

Krug, A. W., Völker, K., Dantzler, W. H., and Silbernagl, S. (2007). Why is D-serine nephrotoxic and alpha-aminoisobutyric acid protective? Am. J. Physiol. Renal Physiol. 293, F382-F390. doi: 10.1152/ajprenal.00441.2006

Labrie, V., Wong, A. H., and Roder, J. C. (2012). Contributions of the D-serine pathway to schizophrenia. Neuropharmacology 62, 1484-1503. doi: 10.1016/j. neuropharm.2011.01.030

Lane, H. Y., Lin, C. H., Green, M. F., Hellemann, G., Huang, C. C., Chen, P. W., et al. (2013). Add-on treatment of benzoate for schizophrenia: a randomized, double-blind, placebo-controlled trial of $\mathrm{D}$-amino acid oxidase inhibitor. JAMA Psychiatry 70, 1267-1275. doi: 10.1001/jamapsychiatry.2013.2159

Lisman, J. E., Coyle, J. T., Green, R. W., Javitt, D. C., Benes, F. M., Heckers, S., et al. (2008). Circuit-based framework for understanding neurotransmitter and risk gene interactions in schizophrenia. Trends Neurosci. 31, 234-242. doi: 10.1016/j. tins.2008.02.005

Lobo, M. K., Covington, H. E., Chaudhury, D., Friedman, A. K., Sun, H., DamezWerno, D., et al. (2010). Cell type-specific loss of BDNF signaling mimics optogenetic control of cocaine reward. Science 330, 385-390. doi: 10.1126/science. 1188472

Lüscher, C., and Malenka, R. C. (2011). Drug-evoked synaptic plasticity in addiction: from molecular changes to circuit remodeling. Neuron 69, 650-663. doi: 10.1016/j.neuron.2011.01.017

Martin, M., Chen, B. T., Hopf, F. W., Bowers, M. S., and Bonci, A. (2006). Cocaine self-administration selectively abolishes LTD in the core of the nucleus accumbens. Nat. Neurosci. 9, 868-879. doi: 10.1038/nn1713

Martineau, M., Shi, T., Puyal, J., Knolhoff, A. M., Dulong, J., Gasnier, B., et al. (2013). Storage and uptake of D-serine into astrocytic synaptic-like vesicles specify gliotransmission. J. Neurosci. 33, 3413-3423. doi: 10.1523/JNEUROSCI. 3497-12.2013 
Massey, P. V., Johnson, B. E., Moult, P. R., Auberson, Y. P., Brown, M. W., Molnar, E., et al. (2004). Differential roles of NR2A and NR2B-containing NMDA receptors incortical long-term potentiation and long-term depression. J. Neurosci. 24, 7821-7828. doi: 10.1523/jneurosci.1697-04.2004

Maze, I., Chaudhury, D., Dietz, D. M., Von Schimmelmann, M., Kennedy, P. J., Lobo, M. K., et al. (2014). G9a influences neuronal subtype specification in striatum. Nat. Neurosci. 17, 533-539. doi: 10.1038/nn.3670

Mendelson, J. H., and Mello, N. K. (1996). Management of cocaine abuse and dependence. N. Engl. J. Med. 334, 965-972. doi: 10.1056/NEJM1996041 13341507

Miya, K., Inoue, R., Takata, Y., Abe, M., Natsume, R., Sakimura, K., et al. (2008). Serine racemase is predominantly localized in neurons in mouse brain. J. Comp. Neurol. 510, 641-654. doi: 10.1002/cne.21822

Mothet, J. P., Parent, A. T., Wolosker, H., Brady, R. O. Jr., Linden, D. J., Ferris, C. D., et al. (2000). D serine is an endogenous ligand for the glycine site of the Nmethyl-D-aspartate receptor. Proc. Natl. Acad. Sci. U S A 97, 4926-4931. doi: 10. 1073/pnas.97.9.4926

Moussawi, K., Pacchioni, A., Moran, M., Olive, M. F., Gass, J. T., Lavin, A., et al. (2009). N-Acetylcysteine reverses cocaine-induced metaplasticity. Nat. Neurosci. 12, 182-189. doi: 10.1038/nn.2250

Nestler, E. J. (2005). The neurobiology of cocaine addiction. Sci. Pract. Perspect. 3, 4-10. doi: 10.1151/spp05314

Nic Dhonnchadha, B. A., Szalay, J. J., Achat-Mendes, C., Platt, D. M., Otto, M. W., Spealman, R. D., et al. (2010). D-cycloserine deters reacquisition of cocaine selfadministration by augmenting extinction learning. Neuropsychopharmacology 35, 357-367. doi: 10.1038/npp.2009.139

Ortinski, P. I., Turner, J. R., and Pierce, R. C. (2013). Extrasynaptic targeting of NMDA receptors following D1 dopamine receptor activation and cocaine selfadministration. J. Neurosci. 33, 9451-9461. doi: 10.1523/JNEUROSCI.5730-12. 2013

Panatier, A., Theodosis, D. T., Mothet, J. P., Touquet, B., Pollegioni, L., Poulain, D. A., et al. (2006). Glia-derived D-serine controls NMDA receptor activity and synaptic memory. Cell 125, 775-784. doi: 10.1016/j.cell.2006.02.051

Paul, P., and de Belleroche, J. (2014). The role of D-serine and glycine as coagonists of NMDA receptors in motor neuron degeneration and amyotrophic lateral sclerosis (ALS). Front. Synaptic Neurosci. 16, 6-10. doi: 10.3389/fnsyn. 2014.00010

Podda, M. V., Riccardi, E., D’Ascenzo, M., Azzena, G. B., and Grassi, C. (2010). Dopamine D1-like receptor activation depolarizes medium spiny neurons of the mouse nucleus accumbens by inhibiting inwardly rectifying $\mathrm{K}^{+}$currents through a cAMP-dependent protein kinase A-independent mechanism. Neuroscience 167, 678-690. doi: 10.1016/j.neuroscience.2010.02.075

Potier, B., Turpin, F. R., Sinet, P. M., Rouaud, E., Mothet, J. P., and Videau, C. (2010). Contribution of the D-serine-dependent pathway to the cellular mechanisms underlying cognitive aging. Front. Aging Neurosci. 2:1. doi: 10. 3389/neuro.24.001.2010

Rosenberg, D., Artoul, S., Segal, A. C., Kolodney, G., Radzishevsky, I., Dikopoltsev, E., et al. (2013). Neuronal D-serine and glycine release via the Asc-1 transporter regulates NMDA receptor-dependent synaptic activity. J. Neurosci. 33, $3533-$ 3544. doi: 10.1523/jneurosci.3836-12.2013

Sacchi, S., Rosini, E., Pollegioni, L., and Molla, G. (2013). D-amino acid oxidase inhibitors as a novel class of drugs for schizophrenia therapy. Curr. Pharm. Des. 19, 2499-24511. doi: 10.2174/1381612811319140002

Sasabe, J., Miyoshi, Y., Suzuki, M., Mita, M., Konno, R., Matsuoka, M., et al. (2012). D-amino acid oxidase controls motoneuron degeneration through $\mathrm{D}$-serine. Proc. Natl. Acad. Sci. U S A 109, 627-632. doi: 10.1073/pnas.1114639109

Sesack, S. R., Aoki, C., and Pickel, V. M. (1994). Ultrastructural localization of D2 receptor-like immunoreactivity in midbrain dopamine neurons and their striatal targets. J. Neurosci. 14, 88-106.

Stevens, E. R., Esguerra, M., Kim, P. M., Newman, E. A., Snyder, S. H., Zahs, K. R., et al. (2003). D-serine and serine racemase are present in the vertebrate retina and contribute to the physiological activation of NMDA receptors. Proc. Natl. Acad. Sci. U S A 100, 6789-6794. doi: 10.1073/pnas.1237052100

Thanos, P. K., Bermeo, C., Wang, G. J., and Volkow, N. D. (2009). D-cycloserine accelerates the extinction of cocaine-induced conditioned place preference in C57bL/c mice. Behav. Brain. Res. 199, 345-349. doi: 10.1016/j.bbr.2008.12.025
Thomas, M. J., Beurrier, C., Bonci, A., and Malenka, R. C. (2001). Long-term depression in the nucleus accumbens: a neural correlate of behavioral sensitization to cocaine. Nat. Neurosci. 4, 1217-1223. doi: 10.1038/nn757

Torregrossa, M. M., Sanchez, H., and Taylor, J. R. (2010). D-cycloserine reduces the context specificity of pavlovian extinction of cocaine cues through actions in the nucleus accumbens. J. Neurosci. 30, 10526-10533. doi: 10.1523/JNEUROSCI. 2523-10.2010

Turpin, F. R., Potier, B., Dulong, J. R., Sinet, P. M., Alliot, J., Oliet, S. H., et al. (2011). Reduced serine racemase expression contributes to age-related deficits in hippocampal cognitive function. Neurobiol. Aging 32, 1495-1504. doi: 10.1016/j. neurobiolaging.2009.09.001

Verrall, L., Walker, M., Rawlings, N., Benzel, I., Kew, J. N., Harrison, P. J., et al. (2007). d-Amino acid oxidase and serine racemase in human brain: normal distribution and altered expression in schizophrenia. Eur. J. Neurosci. 26, 16571669. doi: 10.1111/j.1460-9568.2007.05769.x

Williams, S. M., Diaz, C. M., Macnab, L. T., Sullivan, R. K., and Pow, D. V. (2006). Immunocytochemical analysis of D-serine distribution in the mammalian brain reveals novel anatomical compartmentalizations in glia and neurons. Glia 53, 401-411. doi: 10.1002/glia.20300

Williams, R. E., and Lock, E. A. (2004). D-serine-induced nephrotoxicity: possible interaction with tyrosine metabolism. Toxicology 201, 231-238. doi: 10.1016/j. tox.2004.05.001

Wolf, M. E., and Tseng, K. Y. (2012). Calcium-permeable AMPA receptors in the VTA and nucleus accumbens after cocaine exposure: when, how and why? Front. Mol. Neurosci. 5:72. doi: 10.3389/fnmol.2012.00072

Wolosker, H. (2011). Serine racemase and the serine shuttle between neurons and astrocytes. Biochim. Biophys. Acta 1814, 1558-1566. doi: 10.1016/j.bbapap.2011. 01.001

Wolosker, H., Blackshaw, S., and Snyder, S. H. (1999). Serine racemase: a glial enzyme synthesizing D-serine to regulate glutamate-N-methyl-D-aspartate neurotransmission. Proc. Natl. Acad. Sci. U S A 96, 13409-13414. doi: 10.1073/pnas. 96.23.13409

Wu, S. Z., Bodles, A. M., Porter, M. M., Griffin, W. S., Basile, A. S., and Barger, S. W. (2004). Induction of serine racemase expression and D-serine release from microglia by amyloid beta-peptide. J. Neuroinflammation 1:2. doi: 10 . 1186/1742-2094-1-2

Yang, F. Y., Lee, Y. S., Cherng, C. G., Cheng, L. Y., Chang, W. T., Chuang, J. Y., et al. (2013). D-cycloserine, sarcosine and D-serine diminish the expression of cocaine-induced conditioned place preference. J. Psychopharmacol. 27, 550-558. doi: 10.1177/0269881110388333

Yang, Y., Ge, W., Chen, Y., Zhang, Z., Shen, W., Wu, C., et al. (2003). Contribution of astrocytes to hippocampal long-term potentiation through release of Dserine. Proc. Natl. Acad. Sci. U S A 100, 15194-15199. doi: 10.1073/pnas.24310 73100

Yashiro, K., and Philpot, B. D. (2008). Regulation of NMDA receptor subunit expression and its implications for LTD, LTP and metaplasticity. Neuropharmacology 55, 1081-1094. doi: 10.1016/j.neuropharm.2008.07.046

Zhang, Z., Gong, N., Wang, W., Xu, L., and Xu, T. L. (2008). Bell-shaped D-serine actions on hippocampal long-term depression and spatial memory retrieval. Cereb. Cortex 18, 2391-2401. doi: 10.1093/cercor/bhn008

Conflict of Interest Statement: The authors declare that the research was conducted in the absence of any commercial or financial relationships that could be construed as a potential conflict of interest.

Received: 30 May 2014; accepted: 29 June 2014; published online: 16 July 2014. Citation: D'Ascenzo M, Podda MV and Grassi C (2014) The role of D-serine as coagonist of NMDA receptors in the nucleus accumbens: relevance to cocaine addiction. Front. Synaptic Neurosci. 6:16. doi: 10.3389/fnsyn.2014.00016

This article was submitted to the journal Frontiers in Synaptic Neuroscience.

Copyright (c) 2014 D'Ascenzo, Podda and Grassi. This is an open-access article distributed under the terms of the Creative Commons Attribution License (CC BY). The use, distribution or reproduction in other forums is permitted, provided the original author(s) or licensor are credited and that the original publication in this journal is cited, in accordance with accepted academic practice. No use, distribution or reproduction is permitted which does not comply with these terms. 